\title{
Asociación de linfomas malignos con herpes virus I y II.
}

ALARCON-ROZAS Ashley Efraín*, SALAS SÁNCHEZ Fernando**, VILLACRES VELA Karina, GUEVARA GUEVARA Julio***

\section{SUMMARY}

Objectives: To know the prevalence of seropositivity for herpes virus I and II in patients with malignant non Hodgkin lymphoma (NHL), and the association with the cell lineage (B or T). Patients and Methods: We considered 60 new or in first recurrence patients with NHL at the Hospital Nacional Guillermo Almenara from August 1999 to December 2000. We analyzed the data by descriptive biostatistics in Epi-Info program. Results: Median age was 59 years, two thirds were men, $65 \%$ were new patients and the primary site was extranodular in $58 \%$ of the cases. $80 \%$ were NHL to B cells, and more than $90 \%$ in advance stage (III and IV), none of them were positive for IgM herpes virus I or II and $25 \%$ were positive for IgG I or II ( $2 / 3$ positive for IgG I) and more than $90 \%$ of them were for B cell. Conclusion: The prevalence of seropositivity for herpes I or II in patients with NHL was $25 \%$, usually associated to B cells, on the other hand we have an elevated percentage of $\mathrm{T}$ cell NHL $(\mathbf{2 5 \%})$ as well as extranodular NHL $(58 \%)$. We need more studies specially a case-control study to define the association of herpes virus I or II with NHL. ( Rev Med Hered 2002; 13: 40-43 ).

KEY WORDS: Herpes virus, lymphoma, non Hodgkin lymphoma.

\section{RESUMEN}

Objetivos: Conocer la prevalencia de la seropositividad para herpes virus I y II en pacientes con linfomas non Hodgkin y su asociación con el linaje celular (B ó T). Pacientes y métodos: Se tomó una muestra de 60 pacientes en el Hospital Almenara de Agosto de 1999 a Diciembre del 2000 todos ellos pacientes con diagnostico establecido de linfoma non Hodgkin nuevos o en primera recaída, el análisis se realizó mediante bioestadística descriptiva. Resultados: La mediana de la edad fue de 59 años, 2/3 fueron varones, $65 \%$ pacientes nuevos y el linfoma primario fue extraganglionar en un 58\% de los casos. El 80\% de los linfomas fueron a células B y mas del $90 \%$ en estadios avanzados (III y IV), ningún caso fue positivo para IgM herpes I o II y $25 \%$ tuvieron serología positiva IgG para herpes I o II (2/3 positivos para IgG I) de los cuales el 93\% fueron a células B. Conclusiones: La prevalencia de seropositividad para herpes virus I y II en pacientes con linfoma non Hodgkin es del 25\%, mayormente asociado a células B, además de tener un porcentaje considerable de linfomas a células T (25\%) y linfomas extranodales (58\%); para evaluar la posibilidad de asociación entre este virus y los linfomas requerimos de un estudio caso-control. ( Rev Med Hered 2002; 13: 40-43 ).

PALABRAS CLAVE: Herpes, virus, linfoma, linfoma no Hodgkin.

\footnotetext{
* $\quad$ Medico Residente Oncología Clínica. Hospital Nacional Guillermo Almenara.

** Jefe del Departamento de Oncología. Hospital Nacional Guillermo Almenara.

*** Medico Asistente del Servicio de Oncología. Hospital Nacional Guillermo Almenara.
} 


\section{INTRODUCCION}

Se conoce desde hace mas de medio siglo la asociación de neoplasias malignas con algunos virus, desde aquel insigne experimento de Rous en el siglo pasado; posteriormente se identificaron algunos virus relacionados a los linfomas malignos siendo el primero en ser conocido el Epstein Barr Virus (EBV), cuyo secuencia de DNA se identifico en linfomas B y de estos en los más agresivos (linfomas de Burkitt) en pacientes pediátricos del Africa, presentando una alteración del cMyc principalmente (1). Adicionalmente han aparecido nuevos virus relacionados a los linfomas o a un subgrupo de ellos en especial, hablamos del virus de la hepatitis $\mathrm{C}$, del HTLV-1 relacionado mayormente a la leucemia de células T del adulto (ATL) y por supuesto al desarrollo de neoplasias linfoproliferativas en pacientes HIV positivos (2), en quienes los linfomas toman un especial comportamiento existiendo además del virus HIV una coinfección con otros DNA virus, especialmente el virus del sarcoma de Kaposi actualmente conocido como herpes virus 8 (HHV8)(3,4), el cual se asocia a linfomas de cavidades.

Los virus herpes, presentan varios subserotipos por lo que han sido clasificados como pertenecientes a las familias b e Y . Desde 1986, se han identificado tres nuevos tipos de virus herpes: HHV-6, HHV-7 y HHV-8 $(4,5)$ perteneciendo los 2 primeros a la familia b herpes con comportamientos biológicos y clínicos diferentes pudiendo infectar linfocitos B y T (6,7); mientras el HHV8 , pertenece a la familia $Y$ herpes e infecta solo linfocitos B y comparte secuencias homólogas con el EBV (1). Recordemos también que los herpes virus se han asociado a otras neoplasias tales como el cáncer de cervix en mujeres asociado al HHV-2 y al cáncer de pene en el varón asociado al mismo serotipo.

Sin embargo aún necesitamos de mayores estudios epidemiológicos para conocer la prevalencia de infección por este virus en diferentes grupos étnicos y etareos (2).

La bibliografía no es muy vasta sobre la asociación de HHV I y II con linfomas, en este estudio pretendemos mediante un estudio serológico determinar la prevalencia en los linfomas malignos y sus características.

\section{PACIENTES Y METODOS}

El presente es un estudio prospectivo realizado en 60 pacientes enrolados entre agosto de 1999 y diciembre del 2000 en el Hospital Nacional Guillermo Almenara, en Lima Perú (HNGAI).
Los criterios de inclusión fueron:

* Pacientes mayores de 18 años con linfoma no Hodgkin.

* Pacientes nuevos para tratamiento con linfoma no Hodgkin.

* Pacientes en primera recaída de linfoma no Hodgkin.

* Pacientes con estudio histológico o citológico para linfoma no Hodgkin.

Los criterios de exclusión fueron :

* Pacientes menores de 18 años

* Pacientes con mas de una recaída de linfoma no Hodgkin.

* Pacientes con linfoma de Hodgkin

Todos los pacientes tuvieron estudio serológico para herpes I y II, IgG e IgM, cabe señalar que los valores de IgM para HHV I y II son los mismos y esta inmunoglobulina es la misma como marcador en infecciones agudas para ambos serotipos. Los valores a ser considerados positivos se tomaron de acuerdo al rango de nuestro laboratorio, para GI HI de 0.2 a 0.4 ; para GI II de 0.3 a 0.6 ; y para GM de 0.7 a 1.0 Asimismo, se realizaron estudios serológicos para HIV que inicialmente se hizo mediante pruebas de ELISA y de ser positivos mediante pruebas de Western Blot. Todos los pacientes tuvieron una determinación de estadio completo en cuanto a imágenes y bioquímica sanguínea. Los datos fueron almacenados en el programa Excel para Windows 2000, y el análisis de los datos se realizó mediante pruebas de bioestadística descriptiva utilizando el software Epi-Info.

\section{RESULTADOS}

De los 60 pacientes estudiados, 40 fueron varones (67\%) y 20 mujeres (33\%). La mediana en edad para el grupo total fue de 59 años, mientras que solo para los varones fue 57.5 años y para el grupo de mujeres de 59 años, no habiendo diferencias significativas entre ambos grupos (Tabla $\mathrm{N}^{\circ} 1$ ).

Veintiún pacientes ingresaron al estudio en primera recurrencia (35\%) y 39 fueron pacientes nuevos $(65 \%)$ siendo en su gran mayoría (78\%) estadios avanzados (III y IV).

Veinticinco pacientes tuvieron linfomas de origen ganglionar (42\%) y 35 de origen extraganglionar (58\%).

De los linfomas extranodales, los mas frecuentes fueron los del tracto gastrointestinal (44\%) seguido de los linfomas primarios de médula ósea. Cuarentaiocho 
Tabla $N^{0} 1$. Características de los pacientes con linfoma maligno.

$\mathrm{n}(\%)$

SEXO

Masculino

40 (67\%)

Femenino

$20(33 \%)$

\section{PRESENTACION}

- Nuevos

$39(65 \%)$

- Recurrentes

$21(35 \%)$

EDAD (mediana)

59.0

Masculino

57.5

Femenino

59.0

ESTADIO

\section{I}

II

III

IV
$3(5 \%)$

$10(17 \%)$

$18(30 \%)$

$29(48 \%)$
(80\%) fueron a células B y 11 (19\%) a células T y solo 1 a células NK (Tabla $\mathrm{N}^{\circ}$ ); de los linfomas a células $\mathrm{B}$, la mayoría de ellos fueron difusos.

El 100\% de estos linfomas tuvieron serología negativa para IgM HHV I y II, 10 casos (16\%) fueron positivos para IgG I $(\mathrm{T}=1, \mathrm{~B}=9)$ y 5 casos $(8 \%)$ fueron positivos para IgG II $(\mathrm{T}=0, \mathrm{~B}=5)\left(\right.$ Tabla $\left.\mathrm{N}^{\circ} 3\right)$, constituyendo el 93\% de los linfomas a células B con serología positiva. Hubieron dos pacientes con linfoma no Hodgkin de

Tabla $\mathrm{N}^{0} 2$. Tipo celular y localización de los
linfomas no Hodgkin.

\begin{tabular}{ll} 
& $n(\%)$ \\
\hline LOCALIZACION & \\
Nodales & $25(42 \%)$ \\
Extranodales & $35(58 \%)$
\end{tabular}

CELULA AFECTADA

$B$

$48(80 \%)$

T

$11(19 \%)$

NK efusión ambos a células $\mathrm{B}$, solo 1 de ellos fue positivo para IgG I y ambos casos tuvieron serología negativa para HIV

\section{DISCUSION}

El descubrimiento de nuevos virus en la familia herpes ha dado lugar a estudios de secuencia para evaluar la tumorogenicidad de cada serotipo. El EBV actualmente conocido como herpes virus 4 (HHV-4) y el HHV-8 son los que mas se asocian a linfoma no Hodgkin, especialmente el HHV-4 que se asocia con enfermedades como el linfoma de Burkitt, linfoma nasal NK/T, linfomas oportunistas en inmunosuprimidos, enfermedad de Hodgkin, linfoma difuso de células grandes y anaplásicas y finalmente a la enfermedad de Castleman (8). La efusión linfomatosa primaria (PEL por sus siglas en Ingles), inicialmente catalogado como linfoma de cavidades fue reconocido como entidad independiente en 1995 (9).

Los reportes iniciales indican que los linfomas de cavidades fueron exclusivamente vistos en pacientes HIV positivos asociado al HHV-8 también llamado virus del sarcoma de Kaposi y cuya alteración se da a nivel del cMyc afectando casi exclusivamente a células B $(10,11)$. Posteriormente se determinó que la infección por HIV no es esencial para la coinfección de HHV-8 y desarrollo posterior del PEL; sin embargo esta entidad se presenta mayormente en pacientes con estadio de SIDA.

En cuanto al HHV I y II existen estudios donde se les asocia con cáncer de ovario (12) y cuando además se asocia a papiloma virus (HPV) serotipos 16/18 en cervix, desencadena una transformación maligna con un potencial altamente maligno (13); asimismo, en linfomas cerebrales se describe desaparición del virus cuando

Tabla N³. Serología para Herpes virus en pacientes con linfoma maligno.

\begin{tabular}{lrr} 
& POSITIVO & NEGATIVO \\
\hline Herpes $\lg G$ I & 10 & 50 \\
Nodal & 7 & \\
Extranodal & 3 &
\end{tabular}

$\begin{array}{lll}\text { Herpes } \lg G \| & 5 & 55 \\ \text { Nodal } & 2 & \\ \text { Extranodal } & 3 & \end{array}$

Herpes $\lg M \quad 0 \quad 60$ 
recibieron tratamiento con acyclovir (14). Recordemos que los virus HHV I y II son básicamente citolíticos y que pueden permitir hasta un máximo de 6 días de vida a la célula cuando esta es infectada agudamente, además la imposibilidad de su no supervivencia en cultivos de tejidos normales (15), lo que va de acuerdo con nuestros resultados pues el $100 \%$ fueron negativos para infección aguda ( IgM negativos), sin embargo en células cancerosas son capaces de permanecer por tiempo indefinido sin causar lisis $(16,17)$ mediante mecanismos inmunológicos aun no del todo dilucidados

El 25\% de nuestros pacientes presentaron serología positiva para HHV I y II de los cuales los dos tercios correspondieron a IgG I y el resto a IgG II; creemos que de todas maneras es un porcentaje considerable a tomar en cuenta en posteriores estudios. El 60\% (9 pacientes) de los pacientes positivos a IgG I o IgG II fueron linfomas ganglionares; sin embargo, es llamativo el porcentaje de linfomas extranodales en el grupo total lo cual pudiera estar alterando el porcentaje de positividad para los linfomas extranodales debido a que casi un 50\% del total fueron linfomas de esta localización.

Finalmente de este estudio definimos que la prevalencia de positividad para HHV I y II es del $25 \%$ en pacientes con linfoma maligno, quedando por dilucidar si estas características se correlacionan con la alta incidencia de linfomas extranodales; asimismo, en este grupo de estudio llama la atención la alta incidencia de linfomas T que llega a ser un $25 \%$ del total probablemente debido a causas ambientales dentro de los cuales los virus podrían jugar un rol importante.

Creemos importante conocer la prevalencia de infección por este virus en la población general para así establecer una posible asociación con el desarrollo de linfomas malignos, tal como el que se realizó en USA y Europa para el HHV-8 $(18,19,20)$.

\section{Correspondencia:}

\section{Ashley Efrain Alarcon-Rozas}

Mrcal Miller 2345 Apt 03 Lince. Lima 14. Perú.

\section{REFERENCIAS BIBLIOGRAFICAS}

1. Niitsu N, Chizuca A, Sasaki N, Umeda M. Human herpes virus-8 associated with two cases of primary-effusion lymphoma. Ann Hematol 2000; 79:336-339.

2. Fogarty International Center, NIH, Institute Pasteur. Viruses and Human Cancers: Challenges for preventive strategies. Environt Health Perspect 1995; 1003 Suppl 8: 269273.

3. Nador R, Cesarman F, Chadburn A, Dawson D, Ansari M,
Sald J, Knowles DM. Primary effusion lymphoma: a distinct clinic pathologic entity associated with the Kaposi's sarcoma-associated herpes virus. Blood 1996; 88: 645656.

4. Chang Y, Cesarman F, Pessin MS, Lee F, Culpepper J, Knowles DM et al. Identification of herpesvirus-like DNA sequences in AIDS-associated Kaposi\{s sarcoma. Science 1994; 266:1865.

5. Salahuddin SZ, Ablashi DV, Markham PD, Josephs SF, Sturzenegger S, Kaplan M, et al. Isolation of a new virus, HBLV, in patient with lymphoproliferative disorders. Science 1986; 234:596.

6. Wyatt LS, Frenkel N. Human herpes virus 7 is a constitutive inhabitant of adult human saliva. J Virol 1992; 66:3206.

7. Yamanishi K, Okuno T, Shiraki, Takahashi M, Kondo T, Asano Y, et al. Identification of human herpesvirus-6 as a causal agent for exanthema subitum. Lancet 1988;1:1065.

8. Mori S. Human herpes virus and malignancies. Rinisho Byori 2001; 49:775-778.

9. Ansari MQ, Dawson DB, Nador R, et al. Primary bodycavity based AIDS-relates lymphomas. Am J Clin Pathol 1996; 105:21-229.

10.Polito P,Carzonien V, Cilice AM, et al. Structural abnormality of 1q in an AIDS-related body-cavity based lymphoma. Int J Cancer 1996; 67: 588-590.

11.Strauchen JA, Heuser AD, Burnstein D, et al. Body-cavity based malignant lymphoma containing Kaposi sarcoma-associated herpes virus in an HIV-negative men with primary Kaposi sarcoma Ann Intern Med 1996; 125:222-225.

12.Cokic-Damjanovic J, Jovanovic J. Herpes simplex virus and ovarian malignancies. Med Pregl 1995; 48:311-314.

13.Di Paolo JA, Woodworth CD, Cantlec F, Zimovic DB, Bryant J, Kernoes A. Relationship of stable integration of herpes virus simplex-2 Bg/IIN subfragment Xho to malignant transform of HPV-immortalized cervical keratinocites. Int J Cancer 1998; 76:865-867.

14.Ambroster C; Drlicek. Herpes virus type II infection as an exophitic endobronchial tumor. Wien Klin Wochenschr 1995; 107:344-346.

15. Kao Y, Sundin D, Gebhardt B. Persistent infection of a lymphoma cell line by herpes simplex virus Am J Hem 1999; 62:93-98.

16.Rinaldo CR, Richter BS, Black PH, Callery R, Chess L, Hirsh MS. Replication of herpes simplex virus and citomegalovirus in human leukocytes. J Immunol 1978; 120:130-136.

17. Youssufian H, Hammer SM, Hirsh MS, Mulder C Methilation of the virus genome in an in vitro model of herpes simplex virus latency. Proct Natl Acad Scie 1982; 79:2207-2210.

18.Gao SJ, Kinsley I, Li M, et al. KSHV antibodies among Americans, Italians and Ugandans with and without Kaposi's sarcoma. Nat Med 1996; 2:925-928.

19.Kedes D, Operalski E, Busch M, et al . The seroepidemiology of human herpes virus 8: Distribution of infection in KS risk groups and evidence for sexual transmission. Nat Med 1996; 2:918-924.

20.Enbern M, Tolfrestain T, Ghebrekidan h, et al. Seroprevalence of Human herpes virus 8 in different Eritrean population groups. J Clin Virol 1999; 14:167-172. 